Del giro espacial o una historia horizontal del arte Piotr Piotrowski

\title{
DEL GIRO ESPACIAL O UNA HISTORIA HORIZONTAL DEL ARTE ${ }^{1}$
}

\section{ON THE SPATIAL TURN, OR HORIZONTAL ART HISTORY}

\author{
Piotr Piotrowski \\ Polonia
}

Traducción del francés: Berenice Gustavino

Facultad de Bellas Artes. Universidad Nacional de La Plata. Argentina

\section{RESUMEN}

Este artículo es la versión en español de «0n the Spatial Turn, or Horizontal Art History» del historiador del arte polaco Piotr Piotrowski (1952-2015). Fue publicado por primera vez en inglés y en checo en Umění/Art (ก. ${ }^{0}$ 5, 2008, pp. 378-383), revista del Instituto de Historia del Arte de la Academia de Ciencias de la República Checa. En 2014 fue traducido al francés por Katarzyna Cohen e incluido en el volumen de Kantuta Quirós y Aliocha Imhoff (eds.), Géo-esthétique (París: B42). Desiderio Navarro lo tradujo para el Congreso de la Asociación Internacional de Críticos de Arte celebrado en Cuba en 2016. Fue publicado luego en los sitios web de Polonica Hispanica y de la revista Criterios. En 2017 fue incluido en el tercer tomo de Denken Pensée Thought Myśl, e-zine de Pensamiento Cultural Europeo. Esta traducción se realizó a partir de la versión francesa de 2014

\section{Palabras clave}

Historia del arte; historia horizontal; geohistoria; historia global; arte moderno

\begin{abstract}
This article is the Spanish version of «0n the Spatial Turn, or Horizontal Art History» by the Polish art historian Piotr Piotrowski (1952-2015). It was published for the first time in English and in Czech in Uměni / Art (N. ${ }^{0}$ 5, 2008, pp. 378-383), journal of the Institute of Art History of the Academy of Sciences of the czech Republic. In 2014 it was translated into French by Katarzyna Cohen and included in the volume by Kantuta Quirós and Aliocha Imhoff (eds.), Géo-esthétique (Paris: B42). Desiderio Navarro translated it for the Congress of the International Association of Art Critics held in Cuba in 2016. It was later published on the Polonica Hispanica websites and the Criterios magazine. In 2017 it was included in the third volume of Denken Pensée Thought Myśl, e-zine de Pensamiento Cultural Europeo. This translation was made from the French version of 2014
\end{abstract}

\section{KEYWORDS}

History of art; horizontal story; geohistory; global history; modern Art 
Escrito por un grupo eminente de autores ligados a la revista trimestral October, publicado hace algunos años, el libro Art since 1900 (Foster, Krauss \& Bois, 2004), constituye sin ninguna duda una de las mejores síntesis sobre el arte del siglo XX. Este libro contiene una cantidad fenomenal de informaciones histórico-artísticas, clasificadas cronológicamente por décadas, y de las que algunos capítulos-décadas, focalizados sobre acontecimientos artísticos mayores de un período dado, fueron analizados a través de los procesos intelectuales del período en cuestión y no como manifestaciones autónomas. La narración histórica se encuentra entrecortada por discusiones de autores que toman la forma de un debate en torno a una "mesa redonda». Sus análisis se apoyan sobre los últimos métodos de investigación desarrollados, en muchos casos, por los autores mismos de ese libro. Cada sección dispone, además, de una lista de referencias bibliográficas complementarias y de reenvíos hacia otras rúbricas de ese manual. Esto permite seguir los procesos artísticos concretos, las sucesiones de acontecimientos o, lo que es más, la evolución del arte de diferentes artistas, liberándose de la estructuración continua de las secciones de la publicación. El diccionario de términos histórico-artísticos (glossary) del arte del siglo XX, el índice, así como una importante bibliografía se encuentran al final del libro. En una palabra, Art since 1900 es un excelente manual universitario. Comúnmente utilizado en la enseñanza universitaria, es muy útil durante los estudios sobre el arte del siglo pasado, organizado de manera clara y escrito en un idioma contemporáneo. Es conveniente, sin embargo, preguntarse por la geografía.

Art Since 1900 es, sin ninguna duda, un manual del arte occidental, del arte nacido en los centros políticos y culturales occidentales, como París, Berlín, Viena, Londres o Nueva York. Esto no significa que al libro le falten ejemplos de las artes desarrolladas en las fronteras de Occidente o más allá de esas zonas. Sin hablar de Rusia, del rol de Moscú o de San Petesburgo (o Petrogrado), el lector encontrará informaciones sobre las interrogaciones surgidas del arte del siglo XX en Brasil, México, Japón o incluso Europa Central. Se trata, probablemente, de la primera publicación de este género. El libro amplía la geografía artística del arte del siglo pasado y sirve a la vez de manual universitario. El problema es que esta publicación no pone en cuestión las bases implícitas de la geografía artística moderna e ignora la perspectiva de la geografía crítica y lo que Thomas DaCosta Kaufmann denomina "geohistoria» (Kaufmann, 2004; Kaufmann \& Pilliod, 2005). No devela, entonces, las significaciones históricas del espacio o del lugar específico donde es creado ese arte, en una palabra, no deconstruye la relación entre el centro y los márgenes de la historia del arte mundial moderno. El grupo de investigadores del que surgen los autores del libro contribuyó fuertemente a la revisión de los paradigmas en historia del arte, fundando su propio proyecto de una historia del arte crítica, a partir de una movilización de las ciencias sociales, del psicoanálisis, del feminismo, de la teoría queer, etcétera. Sin embargo [...] los autores del libro no retomaron a gran escala las críticas de la geografía artística moderna ni intentaron revisar las premisas de su propia metodología. Es así que las descripciones del arte, por fuera de las fronteras de Europa Occidental y de América, presentes en ese libro, son hechas, por así decir, a través del prisma occidental. En este contexto, Rusia, cuya influencia sobre el desarrollo de la vanguardia mundial (occidental) es difícil de estimar, es una excepción. Pero Rusia, y en particular la historia de la primera gran vanguardia, es parte desde hace mucho tiempo, en Occidente, de los cánones del arte del siglo XX, al menos desde que Alfred Barr cayó bajo el encanto de ese arte. Su inclusión en la narración histórica es entonces más una obligación profesional que una innovación. Al contrario, la historia del arte de otras regiones geográficas es presentada como un fragmento de una historia del arte universal de la que los modelos nacieron en Occidente, lo que revela una visión occidentalo-céntrica de la historia del arte así como de las premisas modernistas de la geografía artística.

Consideraría este tipo de narración historiográfica como «vertical». Esta se caracteriza antes que nada por una cierta jerarquización. El corazón del arte moderno - es decir, el centro, una o más ciudades donde se crean los paradigmas de la tendencia artística concreta- está constituido esencialmente por ciudades occidentales, como Berlín, París o Nueva York. Es desde esos centros que los modelos del arte moderno irradian en el mundo e influyen sobre las periferias. El arte en el centro define, entonces, un cierto paradigma; mientras que el arte de las periferias es la adaptación del modelo creado en la metrópolis artística. Los cánones artísticos, la jerarquía de valores, las normas estilísticas son creados en el centro y, en el mejor de los casos, las periferias se los apropian. Puede suceder, por supuesto, que en los márgenes culturales de la geografía artística aparezcan artistas de excepción, 
pero ellos no ganan reconocimiento, cierta consagración en la historia del arte más que en los centros, a través de las exposiciones que organizan allí y de los libros que allí publican. Es esto lo que les sucede a dos excelentes constructivistas polacos, Katarzyna Kobro y Władysław Strzemiński, o incluso, en Checoslovaquia, a los dos formidables surrealistas, Toyen o jindřich Štyrský. Naturalmente, estos artistas eran reconocidos por sus pares y tratados como iguales (por ejemplo, André Breton, en una conferencia en Praga, el 29 de marzo de 1935, expuso el hecho de que el surrealismo se desarrollaba en paralelo en Praga y en París) (Breton, 1972). En efecto, los artistas de la vanguardia internacional no percibían la escena artística en una perspectiva vertical. Para los dadaístas, Bucarest o Tokio tenían tanta importancia como Berlín o Zurich. Es la historia del arte la que ha elaborado un discurso jerarquizante, «vertical», que organiza la geografía artística en torno de centros y de periferias.

Para sostener este mismo ejemplo me gustaría hablar de una notable historia del dadaísmo redactada por Stephen Foster. Esta se compone de varios volúmenes y el cuarto contiene la descripción de lo que sucedió por fuera del centro (occidental). Su título es significativo: en The Eastern Dado Orbit (1998) encontramos la descripción del movimiento Dadá tanto en Europa Occidental como en Europa Central y en Japón. ${ }^{2}$ Lo que es significativo, es que lo que está por fuera del centro es calificado de oriental y el llamado Oriente es definido de una manera muy amplia: de Praga hasta Tokio. Es en este tipo de construcción vertical de la historia del arte que se inscribe sin ninguna duda una actitud de "orientalización» de la cultura de los «Otros», según la definición de Edward Said (1978).

Dirigir una crítica al paradigma de investigación «vertical» no es tan simple. Desde luego, existen numerosas publicaciones consagradas al arte creado por fuera de los centros artísticos occidentales, en Europa Central, en América del Sur o en Asia que, con éxito diverso, enfrentan los problemas metodológicos que conciernen a las relaciones Este/Oeste o bien Norte/Sur, pero el problema es mucho más profundo: ¿existe un arte moderno no occidental? Y si existe, ¿cuál es su modo de existencia? El modernismo y sus «mutaciones» como el antimodernismo y el posmodernismo fueron, por definición, ante todo, occidentales, es por esto que el significado modernista estaba dotado de significados universales. Como lo subraya Igor Zabel (1998), las formas y los valores del arte son modernos y, por lo tanto, occidentales. Sin embargo, esas formas y valores no funcionan únicamente en Occidente y en el Norte, sino también en Oriente y en el Sur. Entonces, al considerar la historia del arte «internacional», debemos volver a preguntarnos lo que recientemente planteó Suzana Milevska (2007): ¿puede una historia del arte de ese tipo existir por fuera de las dicotomías geográficas antes mencionadas? (p. 216). Evidentemente no. (En su artículo The Marco Polo Syndrome, Gerardo Mosquera (2005) criticaba el concepto de asimetría cultural, que consiste en decir que Occidente proveé los modelos y que el resto del mundo puede optar entre adoptarlos o ser «tradicionalizado» o «exotizado» en los museos etnográficos: esto no solo es simplista sino que constituye también una herramienta de dominación cultural de los centros). Es cierto que el arte moderno de las regiones colonizadas se desarrolló inspirándose en los modelos llegados de la metrópolis. Sin embargo, para los investigadores que tienen experiencia en este tipo de análisis se volvió evidente que el significado de ese arte supera ampliamente la adaptación, la imitación o bien los «complementos» de ese arte definido por los centros del modernismo.

Uno de los intentos más logrados de acceder a la complejidad de este problema, no a escala de un estudio de caso aislado sino más bien de una amplia síntesis del terreno no occidental y más precisamente de Asia, es el libro de John Clark titulado Modern Asion Art (1998). Allí, Clark describe el arte moderno en Asia y la relación que éste mantiene con el arte de Occidente que el autor denomina «Euroamérica». Clark esbozó un panorama muy detallado señalando, al mismo tiempo, la falta de conocimiento de Occidente sobre el tema. Sin embargo, esta diversidad no resulta únicamente de la diferencia de la política cultural de los países que adoptaron el modelo del modernismo occidental, sino más bien del hecho de que ella deriva de procesos culturales más profundos que se producen en lugares determinados. En efecto, según Clark, esta influencia «euroamericana» no es más que un elemento a tomar en consideración por un historiador del arte de la región. Otro elemento es la dinámica interna de una cultura dada, sus necesidades selectivas y el rol jugado por las «transferencias» culturales en ciertos países. 
En otros términos, Clark se interesa tanto por el reflejo del arte occidental en Asia como por la función que este arte y las instituciones artísticas adquirieron en un contexto asiático dado. Se trata de una visión mucho más dinámica de la recepción del arte moderno en Asia que aquella a la que los manuales occidentales de historia del arte nos acostumbraron. El artista, la obra o la cultura de un país dado son para Clark (1998) mucho más los «actores» que los «campos» sobre los que las influencias occidentales aparecen (p. 22). Además, paradójicamente, el estilo artístico occidental es usado, muy a menudo, para marcar la oposición frente al colonialismo cultural y a la dominación imperial de Occidente en las diversas formas de arte neotradicionalista, lo que complica aún más la imagen de la situación local. Esto concierne también a la diferenciación del arte y a la aparición de escuelas locales de estilo "occidental».

Todos los historiadores del arte que trabajan sobre las regiones del mundo marginalizadas encuentran las mismas problemáticas que Clark. Yo mismo hice la experiencia escribiendo una Historia del arte de Europa central y del Este posterior a la Segunda Guerra Mundial (Piotrowski, 2005). Esa región, aunque perteneciese a una Europa dominada por la Unión Soviética, aún era Europa; ese arte aún era europeo, incluso si los contactos con el arte occidental eran difíciles; y esos artistas, aunque se intentara impedirles viajar a la parte occidental de Europa $-y$, sobre todo, al otro lado de la cortina de hierro-, seguían siendo artistas europeos. Si hubiese querido emplear un método vertical de análisis de la cultura artística de Europa Central y del Este, no hubiese sido posible descubrir la especificidad de los significados de ese arte que se desarrolló en condiciones históricas muy diferentes, incluso si, geográficamente, como por ejemplo en Berlín Oriental, se situaba a pocos pasos del Oeste. Escribiendo entonces sobre la historia del arte de esa región, era necesario poner el acento sobre el contexto político de la recepción de los modelos artísticos occidentales, que por momentos podían cambiar completamente la significación de ese arte: informal no significaba lo mismo en Polonia y en Francia, hoppening no tenía la misma definición en Checoslovaquia y en Estados Unidos, el arte conceptual quería decir una cosa en Hungría y otra en Gran Bretaña. Construir el contexto, en cierta forma el «marco» («froming»), en el sentido que Norman Bryson (1992) da a este término, se volvió una herramienta indispensable del aparataje analítico del historiador de esta parte de Europa. En efecto, las diferencias históricas y la fuerte influencia de lo político sobre el arte dieron lugar a la teoría, según Hans Belting (2003), de las «dos vías de la historia del arte europeo» (p. 61). (Paradójicamente, la presión política causaba a menudo una radical despolitización del arte). Sin embargo, un tratamiento demasiado radical de un postulado como ese podría llevar a una lectura errónea de los procesos históricos (Orišková, 2002). Este arte tenía otro significado que el que se le daba en Occidente, incluso si se desarrollaba en la esfera de influencia de la cultura occidental. Además, esas aspiraciones jugaban un rol de remedio político frente a la política cultural oficial de los países comunistas. En consecuencia, no hay que escribir la «segunda vía de la historia del arte», sino más bien formular otro paradigma para la escritura de la historia del arte.

Naturalmente, existe una gran diferencia entre la historia del arte de Asia y la de Europa del Este, sobre todo si las observamos a través del prisma del Otro. Y no me refiero ni siquiera a la gran heterogeneidad de Asia. La historia del arte indio, en su asimilación de las influencias modernistas occidentales, es muy diferente de la historia del arte moderno de Japón. Si suponemos la "exotización» del Otro y de su historia del arte, comparando la posición de Asia y de Europa Central y del Este, estamos frente a posicionamientos totalmente diferentes. El Otro asiático es como el Otro auténtico; el Otro de Europa Central o de Europa del Este es el Otro parcial o el Otro cercano. ${ }^{3}$ Pero esto no siempre fue así como lo prueba el libro de Larry Wolff (1994) que declara que, para la gente del siglo de las Luces, un habitante de Europa del Este (un lituano, un polaco o un ruso) aparece como el Otro auténtico. Pero, en la cultura moderna, el lugar que ocupa ese Otro cercano se encuentra al margen de la cultura europea, fuera del centro, digamos en la provincia, pero siempre en el mismo marco de civilización. El lugar de este Otro auténtico, por contraste, no es el resultado de una estrategia de marginalización sino de una estrategia de colonización. Su identidad es construida bajo la presión de su propia tradición local y de una metrópolis que coloniza ese territorio. Esta diferencia se refleja en la percepción de esos diferentes Otros. Un europeo del Este comparte con su compadre occidental la mirada «orientalizante» sobre el Otro auténtico, tomando en consideración, por el contrario, un

3 La noción de «Otro cercano» fue usada por Bojana Pejić (1999). Pejić se refiere a Boris Groys pero no da ninguna indicación bibliográfica. 
abanico de «diferencias». Mientras que un asiático — sea cual sea su región de origen- percibe Europa - desde su punto de vista - como un pequeño continente más bien homogéneo. Para él, las culturas alemana, húngara o polaca pertenecen todas a la cultura europea, incluso si el nivel de su expansión no es comparable. Un húngaro o un polaco quieren verse a sí mismos y a su arte como europeos, y este fue particularmente el caso durante los años de dominación comunista, donde esto constituía un remedio psicológico contra los intentos de imponer a sus países el modelo artístico soviético. Las culturas asiáticas no muestran tal necesidad de aferrarse a un nodo asiático común. De cierto modo, es incluso al revés, todas tienen una percepción de gran envergadura de las diferencias locales, incluyendo las diferencias en la recepción de la modernidad «Euroamericana» (Clark, 1998). El problema de la historia del arte en América del Sur es completamente otro. Se trata, en principio, de un espacio geográfico bastante homogéneo a nivel lingüístico, al punto de que es posible observarlo como una región más o menos unificada, a diferencia de los países asiáticos o de Europa del Este. Incluso el libro tan popular sobre el tema de la historia del arte de ese continente, escrito por Dawn Ades y titulado Art in Latin Americo (1989), no dedica más que una ínfima parte (además de algunos capítulos) a su división en naciones. A la homogeneidad lingüística de la región corresponde una composición étnica relativamente homogénea. Esto no quiere decir que su cultura, comprendida su cultura visual, sea homogénea. Sin embargo, esas condiciones geohistóricas externas forman un marco de referencia para el arte que es diferente del de Asia o del de Europa del Este. Existe una opinión que afirma que el arte moderno de América Latina estuvo mucho más enredado con la política revolucionaria que el de Europa o el de Asia. Además, presenta un fuerte lazo entre la modernidad y los intentos de construirse una identidad propia, apoyándose siempre sobre tradiciones culturales locales y étnicas (Ades, 1989, pp. 125-126, pp. 195-213).

Por supuesto, como en todas partes por fuera de los centros del arte moderno, o sea, implícitamente de Occidente, también en América del Sur se vio nacer una mezcla de estilos artísticos. Su encabalgamiento perturba el orden «natural», es decir, occidental de la cronología histórico-artística. Estas mutaciones, tanto como las especificidades locales de recepción del arte occidental, provocaron un fenómeno artístico muy original como el surrealismo de América del Sur (la primera fase de este movimiento fue particularmente interesante en México). En efecto, a pesar de los contactos personales con André Breton, es difícil hablar aquí de surrealismo sino más bien de un arte original y local. Tales fenómenos incitan, sin duda, a los historiadores del arte a revisar el tradicional marco occidental de referencia y también a reconocer la dimensión única de la cultura artística latinoamericana, no solo en sus relaciones con Occidente, sino también con el resto del mundo.

Si la historia del arte global debe ser escrita de acuerdo con las exigencias de la "geohistoria» (Kaufmann, 2004; Kaufmann \& Pilliod, 2005), tomando en cuenta las especificidades del significado del arte de las regiones periféricas, debe ser crítica de las narraciones jerárquicas histórico-artísticas de la historia del arte «vertical» y, en consecuencia, debería escribirse en la perspectiva de un paradigma diferente, «horizontal» (Piotrowski, 2006, p. 53). Una historia del arte construida de esta manera debería utilizar, sin duda, el método de la «geografía relacional» según el pensamiento de Irit Rogoff (2003) quien define la geografía en términos de diferencias culturales (p. 53). Percibir la geografía de la cultura de esta manera es un intento de análisis de la relación entre el sujeto y el lugar donde evoluciona. Ni el lugar ni el sujeto, en nuestro caso, la región artística, ni el arte que allí se crea, son entidades estables ni bien formadas. Al contrario, nacen en el seno de un proceso dinámico en la relación con otras regiones y sujetos, con las tradiciones locales así como con influencias externas; la "geografía relacional» es una geografía crítica que rechaza una actitud tradicional esencialista denominada Kunstgeogrophie.

Intentaré esbozar rápidamente un programa para la historia del arte «horizontal» 0 más bien para las historias del arte horizontales, ya que en esta perspectiva es difícil hablar de una sola historia, en oposición a la vertical y jerárquica historia del arte. Hablaremos, más bien, de narraciones históricoartísticas pluralistas.

La deconstrucción de la historia del arte occidental debería ser el punto de partida para elaborar una historia horizontal. Este análisis crítico debería señalar los sujetos hablantes, o sea, aquel que habla, en nombre de quién y para quién. No se trata aquí de disminuir la importancia de la historia del arte occidental, sino más bien de llamar a este tipo de narración por su verdadero nombre como «occidental». Dicho de otro modo, se trata de separar dos términos a menudo tomados el uno por el otro: el arte occidental moderno y el arte universal; se trata aquí de relativizar este relato y de 
ubicarlo - de acuerdo con las reglas de la historia del arte horizontal- al lado de otras narraciones histórico-artísticas. La consecuencia de tal procedimiento podría ser, o más bien debería ser, el cambio de la mirada tradicional sobre las relaciones entre la historia del arte del Otro y «la nuestra» (léase occidental). Como parece evidente que el arte moderno de los Otros se desarrolla bajo la influencia de Occidente, la relación inversa es mucho menos obvia, ya que ella busca respuestas a la pregunta: ¿de qué modos las experiencias del arte no-occidental pueden influir en la historia del arte occidental, o bien, más precisamente en la percepción del arte occidental? Surge entonces una cuestión: ¿cómo el arte al margen cambia la percepción del arte del centro? Yendo aún más lejos, convendría preguntarse: ¿Qué imagen del centro, sitio ocupado habitualmente por el historiador del arte moderno, puede verse desde el no-centro, desde una posición marginal?, según la idea de que se pueden percibir muchas más cosas hallándose en los márgenes.

Desde los márgenes se ven, sobre todo, las imperfecciones del centro. Si el centro se percibe a sí mismo como homogéneo, los márgenes, durante los procesos de apropiación y de transformación para sus propios beneficios de esas categorías, perciben allí las tensiones internas, que pertenecen a su esencia. Parece que existieran categorías de base que homogeinizan la historia del arte moderno escrita a partir de la posición del centro: el canon y el estilo según una corriente artística dada, como el cubismo o el futurismo, etcétera. La historia del arte de las periferias, comprendida en términos de eventos artísticos y de sus análisis y descripciones, se desarrolla tanto dentro del contexto del canon occidental como de sus categorías estilísticas. Los artistas primero, los historiadores del arte después, refieren sus experiencias creativas y analíticas a esas categorías. El canon occidental de una corriente artística dada deviene el punto de referencia de su recepción y transformación en los lugares específicos por fuera del centro. Ahora, esto no es exactamente una medida valorizante, sino más bien un marco histórico en el seno del cual se hacen operaciones más o menos autónomas que, por el resultado de muchos mecanismos locales, crean sus propias jerarquías y dependencias, sus propios cánones. Esos cánones artísticos locales no pueden coincidir entre ellos porque no existe una sola historia del arte de la periferia, existen tantas como existen periferias, incluso si ellas pueden ser negociadas antes que nada en la perspectiva crítica de oposición al centro. Pero si el canon visto desde la periferia deviene relativo, la conclusión es que ese canon podría ser relativizado también en el propio centro. Los historiadores del arte deberían darse cuenta de que es siempre el efecto de una construcción analítica del historiador del arte y que, en tanto tal, tiene un carácter histórico que concierne más al historiador del arte en cuestión que al arte descripto en sí.

Este proceso es aún más visible en la perspectiva de las categorías estilísticas. Ni el arte de la periferia ni sus historias aceptaron jamás esta "pureza» estilística occidental. Existen numerosos ejemplos y las conclusiones que se deducen de estas observaciones son evidentes. Tomemos, por ejemplo, el cubo-futurismo ruso (ya su nombre es muy heterogéneo), el activismo húngaro, el formismo polaco, el indigenismo sudamericano, el vibracionismo inventado por el artista uruguayo Rafael Barradas, el surrealismo que aparece bajo diferentes formas en muchas partes del mundo, el dadaísmo japonés, el arte concreto latinoamericano, las variedades locales del conceptualismo que, a menudo, diferían del modelo lingüístico occidental (anglosajón). Cuando retornamos nuevamente hacia el análisis del arte del centro, enriquecido por la experiencia de la periferia, comenzamos a comprender que el arte conceptual en Occidente no era ni tan ortodoxo ni tan homogéneo como parecía y el modelo lingüístico, en tanto que categoría analítica basada sobre las experiencias del grupo Art and Longuage, no engloba el conjunto de esas manifestaciones. Quiero decir con esto que la historia del arte del centro, que se construye apoyándose sobre la historia mundial del arte moderno, tiene la posibilidad de reconstruir su propia imagen a la luz del estudio de las periferias, de la historia del arte horizontal o de las historias del arte horizontales.

La relativización de la historia del arte occidental, causada entre otras razones por la deconstrucción de las categorías analíticas, pero también de las categorías geográficas tanto como por el proceso de «localización» del centro, debe alentar una actitud análoga en las historias del arte «Otras». El Otro debe también mirarse, definir su propia posición y el lugar desde el que habla. A decir verdad, ocupa una posición mucho más privilegiada que el narrador que se encuentra en el centro, porque este último, a menudo inconscientemente, por consideración a la ideología de la universalización del arte moderno, ignora el significado del lugar, transformándose de esta manera en un instrumento de colonización. Para él, si el arte es universal, el lugar desde donde habla no es importante. El Otro, mucho más consciente del contexto, se da rápidamente cuenta 
del peso de la "geografía relacional», y puede ayudarnos a comprender que no es que hablamos desde ninguna parte, sino desde sitios bien precisos. Porque el centro es también un lugar, o sea, una localidad con sus características legales, nacionales y culturales bien concretas. El sujeto que se encuentra en el centro olvida que se encuentra en el centro, en un lugar claramente definido sobre el mapa del mundo. Esta consciencia le puede ser reenviada por el Otro que justamente no logra olvidar. El historiador del arte moderno argentino, checo o indio conoce perfectamente su posicionamiento. Al contrario, el historiador francés o estadounidense subestima ese saber en nombre de la universalización de su arte.

Aquí, tocamos un problema esencial de la historia del arte horizontal que es su localización. Si observamos la producción de libros sobre la historia del arte moderno podemos fácilmente constatar que, de un lado, estamos en presencia de una «historia del arte moderno» sin localización específica, y, del otro, constatamos la utilización de numerosos adjetivos que describen lugares regionales (como «el arte de América latina», «el arte de Europa del Este») 0, aún con más frecuencia, adjetivos nacionales («historia del arte polaco», «coreano», «mexicano», etcétera). El problema de las narraciones histórico-artísticas nacionales parece ser más característico para el arte por fuera del centro aún si, como intenta convencernos Thomas DaCosta Kaufmann (2002), su génesis se encuentra en otro lado y es mucho más antigua que la historia del arte moderno. De un lado, tenemos entonces las historias del arte de los diferentes países y, del otro, la historia del arte internacional. Este tipo de narración historiográfica devela la verdadera dinámica de la historia del arte moderno. Esto quiere decir que, de un lado, tenemos artistas de estatus internacional, aunque todos vengan de hecho de países específicos y que su arte lleve la marca de sus culturas nacionales (por ejemplo, Pablo Picasso, que era originario de España) y, del otro lado, artistas que permanecen como específicamente nacionales, incluso aunque algunos de ellos hayan ganado renombre internacional (por ejemplo, Władysław Strzemiński, en tanto que constructivista polaco). Este contraste revela, entonces, tensiones de carácter geográfico: de un lado, París seguida por Nueva York, en tanto centros internacionales del arte y, del otro, las metrópolis regionales, fijadas en un marco nacional, como Praga, Tokio o bien Buenos Aires. En la jerarquía histórico-artística, naturalmente, las dos primeras dominan mientras que las otras son relegadas a un segundo plano. Este tipo de localidad está ligada a la estructura de los Estado Nación y a la fórmula moderna del nacionalismo (Smith, 1998). Actualmente, este proceso evoluciona bajo el efecto de los procesos de globalización (Bhabha, 2007), conectados a una visión posmoderna de la realidad y de la transformación de los Estados Nación en organizaciones más cosmopolitas (Beck, 2005). Parece que el concepto de «localidad» ya no está ligado a un lugar específico sino que trasciende las fronteras, como sostiene Arjun Appadurai (1996). Poco importa el grado de precisión de esta observación, el lugar como etiqueta identitaria no desapareció. Lo que es más, ha adquirido una nueva significación. El alzamiento de fronteras y la globalización de las instituciones del arte (las Bienales, por ejemplo), por un lado, debilitaron los lazos entre los artistas y un sitio dado y, por otro, al contrario, los han reforzado paradójicamente, permitiendo el nacimiento de suertes de «identidades locales en venta». El mundo globalizado necesita este tipo de estrategias, más aún cuando es él quien las ha creado en una óptica comercial o política. Este rol es encarnado, como tan bien describió Mari Carmen Ramírez (1996) basándose en el ejemplo del arte sudamericano, más por los intermediarios de la cultura, que por los historiadores del arte o los comisarios.

Es bueno preguntarse cuáles son las relaciones entre las percepciones posmodernas y poscoloniales de la «nación», o sea de la historia del arte nacional e internacional. Una de las cuestiones principales es el problema ligado al sujeto. De manera general, mientras que el posmodernismo significa una crítica del sujeto, una deconstrucción y una dispersión del sujeto, los estudios poscoloniales defienden más bien la integralidad del sujeto. En la óptica posmoderna, la nación está privada de rasgos esenciales mientras que, según los investigadores poscoloniales, la esencia de la nación parecer ser indispensable para que puedan definirse estrategias de oposición y de crítica de cara al centro. Entonces, en la historia del arte horizontal que se sirve del término "nación», una forma de estabilización y de defensa del sujeto (nacional) parece indispensable. Este tipo de reflexión estaría, entonces, más ligada a la perspectiva poscolonial que a la posmoderna. [...] El arte creado en países determinados no es nunca nacional ni en el sentido étnico ni en el sentido político. La admisión de tal perspectiva sería represiva hacia los otros grupos operando en el marco de un mismo país dominado por una «nación» concreta. [...] Entonces, si la historia del arte horizontal, escrita desde 
una macroperspectiva no puede ignorar los sujetos nacionales y, por eso mismo, está obligada a retomar la crítica del centro, de cierta manera tomando sus defensas, la microperspectiva debería más bien operar una crítica de la subjetividad nacional, deconstruir la nación-sujeto, con el objetivo de defender la cultura de los Otros contra el mainstream nacional.

Para desarrollar mejor esta trama hay que hacerse una pregunta: ¿qué premisas materiales (además de las ideológicas) se sitúan detrás de las construcciones de la historia del arte moderno? Era, presumo, la falta de comunicación directa entre esas culturas. Si se comunicaron entre ellas fue, ante todo, por intermedio del centro. Este fenómeno puede ser observado tanto a escala macro como micro. Las culturas de ciertas regiones en particular (Asia, América del Sur o Europa del Este) miraban a Occidente pero no se miraban entre ellas. Tomaban sus aspiraciones de allí y no de otras periferias. Esto concierne igualmente a ciertas narraciones de las historias del arte nacionales, incluso en el caso de regiones tan pequeñas como Europa del Este. Los polacos no saben gran cosa de la historia del arte rumano, incluso la ignoran anteponiendo la superioridad de su propia cultura comparada con la cultura occidental. Esto es válido también para los checos que conocen poco y nada de la historia del arte ucraniano, etcétera. El Otro mira al Amo y no a otro Otro, adoptando inconscientemente la jerarquía del centro de la que es víctima. Si existe entre ellos algún intercambio de valores, de experiencias o de saberes, es únicamente por intermedio del Amo, o sea de Occidente que, por ese medio, vuelve al Otro creíble a los ojos de un otro Otro.

Por supuesto, la situación de los contactos recíprocos entre el centro y las localidades definidas como nacionales ha cambiado. La cultura moderna se caracterizaba por una tensión nacional-internacional, la cultura actual posmoderna es globalizada, funciona en el marco de doctrinas multiculturales y opta por otro vocabulario. En una arena global, la identidad gana en significado. El modernismo huía de las identidades individuales, de todas las identidades en regla general -étnica, local, sexual, racial, etcétera - en nombre de las utopías universales de la unidad. Ya el adjetivo «internacional» significaba un estado «entre» o bien «fuera» o bien «encima» de las características nacionales o de las identidades nacionales (por ejemplo, el «estilo internacional», la «escena internacional»). Esta retórica escondía el imperialismo de Occidente que se manifestaba ya en el nivel primario, en el nivel del idioma que esta comunidad «internacional» hablaba. Este fue primero el francés, luego el inglés. Sin embargo, una nueva perspectiva impone nuevas estrategias y la caída de una utopía universalista, entre otras, a la luz de los conflictos globales, obliga a adoptar una marca identitaria, al menos como punto de partida. El ejemplo de esta segunda posición podrá ser la interpretación artística de artistas, como Marina Abramović o llya Kabakov, para los que las fuentes nacionales o locales de sus artes son importantes para poder descifrar el significado de ese arte pero, contrariamente a sus predecesores, no los encierran en el marco de un discurso «exótico» (como, por ejemplo, Diego Rivera trabajando en Estados Unidos) ni niegan el rol de las influencias. Además, esta tendencia favorece la reconstrucción de las fuentes nacionales de numerosas ideas de vanguardia que fueron escamoteadas por el paradigma de un modernismo internacional, del que un ejemplo podría ser el análisis de la obra de Marcel Duchamp, en el contexto de la tradición francesa, o de Kazimir Malévich, en el contexto de la tradición rusa.

Es claro que esto no es una nueva tendencia, pero si recordamos los estudios de estos dos artistas en los años 1930, 1940 o 1950, no encontraremos muchas huellas de la contextualización de sus obras. Esta aparece más tarde. Es en esta óptica que interviene otra noción, la «transnacionalidad», que no tiene nada que ver con la «internacionalidad».

La noción de transnacionalidad debería ser utilizada para la construcción de una historia del arte horizontal, polifónica, multidimensional, libre de jerarquías geográficas. Un modelo abierto de historia del arte global debería también incluir otros conceptos enraizados en perspectivas distintas de la geografía crítica: perspectivas de género, de grupos étnicos, de subculturas, etcétera. Por otro lado, tales revisiones de la historia del arte, a partir de un punto de vista feminista, fueron propuestas hace varios años. Sin embargo, a menudo estas no perturban el paradigma geográfico-jerárquico de la historia del arte moderno. La escritura de historias del arte transnacionales, o sea, el reconocimiento de valores y de nociones de otra «escala» que la escala nacional-internacional también existe. ${ }^{4}$

La narración regional de la historia del arte de la que hemos hablado más arriba lo prueba. Esto no debe, esto no puede permitir de nuevo la escritura de una única historia del arte mundial horizontal.

4 Otro problema que no se discute acá, pero que hay que considerar, es el de la negociación históricoartística al interior de un discurso local o nacional dado. 
Esto debería más bien conducir al pluralismo de relatos transregionales, a una crítica evidente del relato de la historia del arte "occidentalo-centrada».

Es un desafío importante lanzado a nuestra disciplina, o al menos a un segmento especializado en el arte moderno. Así como la historia del arte moderno horizontal o bien las historias del arte moderno horizontales deben ser una crítica de la historia del arte vertical centralizada, la historia del arte global debería ser una crítica de la historia del arte universal, historia del arte imperial en el sentido estricto del término, que impone a las colonias jerarquías, categorías epistemológicas así como el sistema de valores de la metrópolis. Dicho de otro modo, la historia del arte internacional debería ser horizontal y no vertical.

\section{REFERENCIAS}

Ades, D. (1989). Art in Latin America. The Modern Ero, 1820-1980 [Arte en Iberoamérico, 1820-1980]. New Haven, Estados Unidos; Londres, Inglaterra: Yale University Press.

Appadurai, A. (1996). Modernity at Large. Cultural Dimensions of Globalization [La modernidad desbordada. Dimensiones culturales de la globalización]. Minnesota, Estados Unidos: University of Minnesota Press.

Beck, U. (2005). Power in the Global Age: A New Political Economy [Poder en la era global: una nuevo economía político]. Cambridge, Inglaterra: Polity Press.

Belting, H. (2003). Art History after Modernism [La historia del arte después de la modernidad]. Chicago, Estados Unidos; Londres, Inglaterra: Chicago University Press.

Bhabha, H. (2007). Preface to the Routledge Classics Edition. En The location of culture [El lugar de lo cultura] (pp. 9-25). Londres, Inglaterra; Nueva York, Estados Unidos: Routledge.

Breton, A. (1972). Position politique du surréalisme [Posición político del surrealismo]. Paris, Francia: Denoel-Gonthier.

Bryson, N. (1992). Art in Context [Arte en contexto]. En R. Cohen (Ed.), Studies in Historical Change. Virginia, Estados Unidos: The University of Virginia Press.

Clark, J. (1998). Modern Asion Art [Arte moderno asiótico]. Honolulu, Estados Unidos: University of Hawai'i Press.

Foster, S. C. (1998). The Eastern Dada orbit: Russia, Georgia, Ukraine, Central Europe and Japan [La órbita de Dada en los países del Este: Rusia, Georgia, Ucrania, Europa Central y Japón]. En Janecek, G., Toshiharu, 0. (Eds.). Crisis and the Arts. The History of Dada, Vol 4. Nueva York, Estados Unidos: G. K. Hall \& Co.

Foster, H., Krauss, R., Bois, Y. (2004). Art since 1900: Modernism, Antimodernism, Postmodernism [Arte desde 1900: modernidad, antimodernidad, posmodernidad]. Londres, Inglaterra: Thames \& Hudson.

Kaufmann, T. (2002). National Stereotypes, Prejudice, and Aesthetic Judgments. En M. Holy, K. Moxey (Eds.), Art History, Aesthetics and Visual Studies [Estereotipos nacionales, prejuicios y juicios estéticos] (pp. 71-84). Massachusetts, Estados Unidos: Sterling and Francine Clark Art Institute.

Kaufmann, T. (2004). Toward a Geography of Art [Hacio una geografía del arte]. Chicago, Estados Unidos y Londres, Inglaterra: The University of Chicago Press.

Kaufmann, T. y Pilliod, E. (Eds.). (2005). Time and Place: Essays in The Geohistory of Art [Tiempo y Iugar: Ensayos sobre la geohistoria del arte]. Aldershot, Inglaterra; Nueva Jersey, Estados Unidos: Ashgate Publishing Co.

Milevska, S. (2007). Is Balkan Art History Global? En J. Elkins (Ed.), Is Art History Global? [¿Es global la historia del arte de los Balcanes?]. Nueva York, Estados Unidos: Routledge. 
Mosquera, G. (2005). The Marco Polo Syndrome. Some Problems around Art and Eurocentrism [El síndrome de Marco Polo. Algunos problemas alrededor de arte y eurocentrismo]. En Z. Kocur, S. Leung (Eds.), Theory in Contemporary Art since 1985 (pp. 218- 225). Londres, Inglaterra; Malden, Estados Unidos: Blackwell Publishing.

Orišková, M. (2002). Dvojhlasné dejiny umenia [Dos voces en la historia del arte]. Bratislava, Eslovaquia: Petrus.

Pejić, B., Elliot, D. (Eds.). (1999). Art and Culture in post-Communist Europe [Arte y Cultura en la Europa post-Comunista]. Estocolmo, Suecia: Moderna Museet.

Piotrowski, P. (2005). Awangarda w cieniu Jałty: Sztuka w Europie Środkowo-Wschodniej w latch 19451989 [Vonguardia en la sombra de Yalto. Arte en Europo del Este, 1945-1989]. Poznań, Polonia: Dom Wydawniczy Rebis.

Piotrowski, P. (2006). On 'Two Voices of Art History'. En P. Piotrowski, K. Bernhardt, Katja (Eds.), Grenzen überwindend. Festschrift für Adam S. Labudo zum 60. Geburstog [Sobre los dos voces en la historio del arte] (pp. 42-56). Berlin: Lukas Verlag.

Ramírez, M. C. (1996). Brokering Identities: Art Curators and the Politics of Cultural Representations. En R. Greenberg, B. W. Ferguson, S. Nairne (Eds.), Thinking about Exhibitions [Mediación identitario: Ios curadores del arte y las políticas de representoción cultural] (pp. 21-38). Londres, Inglaterra; Nueva York, Estados Unidos: Routledge.

Rogoff, I. (2003). Engendering Terror. En U. Biemann (Ed.), Geography and the Politics of Mobility [Engendrando el terror]. Viena, Austria y Colonia, Alemania: Generali Foundation y Verlag der Buchhandlung Walter Koenig, pp. 53.

Said, E. W. (1978). Orientolizm [Orientalismo]. Poznán, Polonia: Zysk.

Smith, A. D. (1998). Nationalism and Modernism. A Critical Survey of Recent Theories of Nations and Nationalism [Nacionalismo y Modernidad. Acerca de la idea moderna de Nación]. Londres, Inglaterra y Nueva York, Estados Unidos: Routledge.

Wolff, L. (1994). Inventing Eastern Europe. The Map of Civilization on the Mind of the Enlightenment [Inventando Europa del Este. El mapa de la civilización en la mente de la Ilustración]. Stanford, Estados Unidos: Stanford University Press.

Zabel, I. (1998). «We» and The «Others». En E. Cúfer, V. Misiano (Eds.), Interpol. The Art Show Which Divided East and West [«Nosotros» y los «Otros»]. Ljubljana, Eslovenia; Moscú, Rusia: IRWIN y Moscow Art Mogozine 